\title{
Pre- and Postweaning Performance of Holstein Female Calves Fed Milk Through Step-Down and Conventional Methods
}

\author{
M. A. Khan, ${ }^{* 1}$ H. J. Lee, ${ }^{* 2}$ W. S. Lee, ${ }^{*}$ H. S. Kim, ${ }^{*}$ S. B. Kim, ${ }^{*}$ K. S. Ki, ${ }^{*}$ J. K. Ha,† H. G. Lee,† and Y. J. Choi† \\ ${ }^{*}$ Dairy Cattle Research Division, National Livestock Research Institute, Cheonan, 330-880, Republic of Korea \\ †School of Agricultural Biotechnology, Seoul National University, Seoul, 151-742, Republic of Korea
}

\begin{abstract}
Milk consumption, dry feed intake, body weight (BW) gain, occurrence of diarrhea, and selected blood metabolites were studied in female Holstein calves fed milk either through conventional or step-down (STEP) methods. In conventional method, the calves $(n=20)$ were fed colostrum and then milk at the rate of $10 \%$ of BW for the entire period of $45 \mathrm{~d}$. In STEP method, the calves $(\mathrm{n}=20)$ were given colostrum and then milk for $25 \mathrm{~d}$ at the rate of $20 \%$ of $\mathrm{BW}$, which was reduced (between $\mathrm{d} 26$ to 30 ) to $10 \%$ of $\mathrm{BW}$ for the remaining $15 \mathrm{~d}$. The calves fed through conventional and STEP methods were weaned gradually by diluting milk with water between $\mathrm{d} 46$ and 50 . Feed intake and BW of the calves were monitored until $90 \mathrm{~d}$ of age. The STEP calves consumed $92.3,19.4$, and $62.4 \%$ more milk than conventionally fed calves during pre-STEP (d 1 to 30 ), postSTEP (d 31 to 50), and preweaning (d 1 to 50) periods, respectively. Consumption of starter and hay were greater during the pre-STEP period and lesser during the post-STEP and postweaning (d 51 to 90 ) periods in calves provided milk using conventional method compared with STEP-fed calves. Body weight gain, dry matter intake, and feed efficiency of calves were greater in those on the STEP method than on the conventional method. Lesser blood glucose and greater blood urea nitrogen at weaning (d 50) and postweaning (d 60) possibly indicated a better functioning rumen in calves fed milk through The STEP method than those fed conventionally. Occurrence of diarrhea was higher during wk 3 and 4 of age in calves fed milk through conventional method compared with STEP-fed calves. In conclusion, STEP milk feeding may prevent the problems of depressed solid feed intake associated with ad libitum milk feeding and of poor BW gain with conventional milk feeding in dairy calves.
\end{abstract}

Key words: milk feeding, weaning, starter intake, diarrhea

Received May 1, 2006.

Accepted October 4, 2006.

${ }^{1} \mathrm{M}$. A. Khan conducted this study as part of postdoctoral research.

${ }^{2}$ Corresponding author: dadim922@rda.go.kr

\section{INTRODUCTION}

Amount and method of milk feeding to dairy calves could affect physiological, immunological, behavioral, and economic traits. The amount of milk fed to dairy calves during the preweaning period not only influences dry feed consumption, growth, and health (Appleby et al., 2001) but also gut development (Anderson et al., 1982), mammary growth, and capacity of milk production (Bar-Peled et al., 1997).

In a conventional system, calves are separated from their dams and fed a restricted quantity of colostrum and then milk using buckets or nipples. Milk feeding through a nipple allows calves to express natural sucking behavior (Hammell et al., 1988) and reduces crosssuckling when they are grouped together (Flower and Weary, 2001). The recommended amount of milk for dairy calves is $10 \%$ of BW daily. This restricted milk feeding is generally associated with depressed performance because of low nutrient availability (Egli and Blum, 1998; Appleby et al., 2001), depressed behavior (Chua et al., 2002), poor health (Huber et al., 1984), and reduced productivity of dairy calves (Pollack et al., 1993).

In recent past, a few attempts have been made to improve the milk supply to dairy calves through ad libitum milk feeding by a nipple attached to a container (Appleby et al., 2001; Jasper and Weary, 2002) or using an automatic feeding system (Hammon et al., 2002). These studies have revealed greater milk consumption and BW gain in ad libitum-fed compared with restricted-fed calves. Jasper and Weary (2002) reported $89 \%$ more milk consumption and $63 \%$ more $\mathrm{BW}$ gain at weaning in calves fed ad libitum than those fed conventionally. However, ad libitum milk consumption during preweaning can reduce or delay the solid feed consumption (Fiems et al., 1982; Thickett et al., 1983; Appleby et al., 2001; Hammon et al., 2002). Less consumption of solid feed by the calves fed milk ad libitum is associated with poor postweaning performance, probably because of delayed ruminal development (Baldwin et al., 2004). Furthermore, the lower solids intake when calves drink milk ad libitum leads to a postweaning lag in growth (Bøe and Havrevoll, 1993). Poor growth and 
Table 1. Chemical composition of calf starter (CS), mixed grass hay (MGS), and klein grass hay (KGS) on a DM basis

\begin{tabular}{|c|c|c|c|}
\hline $\begin{array}{l}\text { Composition, } \\
\%\end{array}$ & CS & $\mathrm{MGS}^{1}$ & KGS \\
\hline DM & $88.9 \pm 0.21$ & $91.01 \pm 0.40$ & $91.19 \pm 0.57$ \\
\hline $\mathrm{CP}$ & $22.45 \pm 0.33$ & $13.71 \pm 0.61$ & $9.77 \pm 0.41$ \\
\hline $\mathrm{TDN}^{2}$ & $72.3 \pm 1.20$ & $54.1 \pm 1.04$ & $56.45 \pm 1.10$ \\
\hline NDF & $12.1 \pm 0.62$ & $65.4 \pm 2.62$ & $54.5 \pm 1.80$ \\
\hline $\mathrm{ADF}$ & $5.97 \pm 0.52$ & $36.5 \pm 2.1$ & $26.1 \pm 1.87$ \\
\hline Ash & $3.70 \pm 0.15$ & $6.73 \pm 0.11$ & $7.2 \pm 0.11$ \\
\hline $\mathrm{Ca}$ & $0.17 \pm 0.02$ & $0.67 \pm 0.1$ & $0.51 \pm 0.04$ \\
\hline $\mathrm{P}$ & $0.51 \pm 0.03$ & $0.26 \pm 0.05$ & $0.22 \pm 0.12$ \\
\hline
\end{tabular}

${ }^{1}$ Mixed grass hay contained $43 \%$ orchard grass, $43 \%$ tall fescue, and $14 \%$ white clover on a DM basis.

${ }^{2} \mathrm{TDN}=$ Total digestible nutrients; calculated using the equation of NRC (2001).

welfare with restricted milk feeding and delayed solid feed consumption with ad libitum milk feeding prompt a demand for development of an alternative milk feeding approach for better performance and welfare of dairy calves.

The objective of this study was to compare the effects of step-down (STEP) milk feeding with conventional milk feeding on solid feed consumption, nutrient intake, BW gain, feed efficiency, selected blood metabolites, and occurrence of diarrhea in Holstein female calves during preweaning and postweaning periods.

\section{MATERIALS AND METHODS}

\section{Calves, Management, and Treatments}

This study was conducted at the National Livestock Research Institute, South Korea. Female Holstein calves $(\mathrm{n}=40)$ born during April to May 2005 were separated from their mothers within $2 \mathrm{~h}$ of birth, weighed, and moved into individual pens $(1.5 \times 2.5 \mathrm{~m}$; bedded with wood shavings) where they were fed colostrum (10\% of BW) for the first $3 \mathrm{~d}$. The individual pens were interspersed evenly throughout the calf barn. Pens had solid iron rod sides, with openings in the front and rear to allow calves free access to calf starter, chopped mixed grass hay (MGS; 43\% orchardgrass, $43 \%$ tall fescue, and $14 \%$ white clover on DM basis), and chopped klein grass hay (KGS; Penicum coloratum) from feeding buckets. Chemical composition of calf starter and hays is given in Table 1. Calves were provided free access to water from a bowl drinker in each pen.

All calves were fed whole milk stored in a milk tank at 4 to $6^{\circ} \mathrm{C}$ after milking. The temperature of milk in steel buckets was raised to 36 to $37^{\circ} \mathrm{C}$ using a water bath before feeding to the calves. Colostrum and milk samples were analyzed with a Lactoscope (MK2; Delta
Instruments, Drachten, the Netherlands) that was standardized for colostrum before its analysis. Chemical composition of colostrum and milk is presented in Table 2.

All calves were fed milk using mobile plastic bottles (2 L capacity) fitted with soft rubber nipples. A steel bottle stand was attached to an iron rod at the front side of individual pen at $70 \mathrm{~cm}$ above the floor. At each feeding, a bottle containing milk was fitted into the stand and was removed after feeding. The bottles were washed using an iodine detergent after each feeding, dried, and stored in the inverted position.

For calves $(\mathrm{n}=20)$ fed using conventional method, milk was provided at the rate of $10 \%$ of BW until $45 \mathrm{~d}$ of age. Calves were fed milk twice daily (0800 and 1700 h) in equally divided doses. The calves were weaned gradually by diluting milk with water between 46 and $50 \mathrm{~d}$ of age. The amount of water was increased by $10 \%$ of total volume at each feeding so that on the morning of $d 50$, all the calves received $100 \%$ water. The calves continued to receive water from the milk bottles until d 54 in addition to the water from the bowl drinker that was always available. This weaning method was used to reduce the variation in weight gains and solid feed intake and, thus, provide a more sensitive test of the feeding treatment than would be possible with abrupt weaning (Jasper and Weary, 2002).

For calves $(n=20)$ fed using the STEP method, milk was provided at the rate of $20 \%$ of BW until d 25 of age, and then between d 26 to 30 , this rate was gradually reduced by diluting the milk with water (10\% of volume on each feeding) until a milk-feeding rate of $10 \%$ of BW was achieved. Calves were fed at this rate for the remaining $15 \mathrm{~d}$ of the weaning period. The STEP calves were weaned between d 45 and 50 as described previously for conventional method calves. During the first phase of STEP milk feeding (pre-STEP, from birth to d 30 of age), the calves were fed milk in evenly spaced feeding frequencies (minimum $2 \mathrm{~h}$ between successive feedings) in such a way that each calf did not receive more than $2 \mathrm{~L}$ of milk at each feeding. During the second phase of STEP milk feeding (post-STEP, from d 31 to 50 of age), the calves were fed milk twice daily (0800 and $1700 \mathrm{~h}$ ) in equal divided doses.

After weaning, BW and DMI were monitored until calves were $90 \mathrm{~d}$ of age.

\section{Sampling and Analysis}

Calves were weighed at birth and at 5-d intervals throughout the experiment. Body weight was used to adjust individual milk allowance for all calves throughout the experiment. Milk consumption by each calf was measured daily. Calf starter, MGS, and KGS intakes 
Table 2. Chemical composition (mean \pm SE) of colostrum and milk

\begin{tabular}{lccrr}
\hline & \multicolumn{3}{c}{ Colostrum $^{1}$} \\
\cline { 2 - 4 } Composition, \% & \multicolumn{1}{c}{ Day 1} & \multicolumn{1}{c}{ Day 2} & \multicolumn{1}{c}{ Day 3} & \multicolumn{1}{c}{ Milk $^{2}$} \\
\hline Fat & $5.6 \pm 0.14$ & $4.2 \pm 0.10$ & $3.95 \pm 0.05$ & $3.80 \pm 0.11$ \\
Protein & $17.4 \pm 0.3$ & $8.94 \pm 0.10$ & $5.4 \pm 0.04$ & $3.39 \pm 0.06$ \\
Lactose & $3.21 \pm 0.01$ & $3.68 \pm 0.02$ & $4.3 \pm 0.02$ & $4.70 \pm 0.03$ \\
TS & $26.6 \pm 0.4$ & $17.1 \pm 0.2$ & $14.3 \pm 0.1$ & $12.86 \pm 0.14$ \\
FFA, mEq/dL & $1.6 \pm 0.05$ & $0.96 \pm 0.05$ & $0.85 \pm 0.04$ & $0.70 \pm 0.03$ \\
Citrate, mg/L & $0.06 \pm 0.01$ & $0.16 \pm 0.01$ & $0.15 \pm 0.01$ & $0.17 \pm 0.01$ \\
MUN, mg/dL & ND $^{3}$ & ND & ND & $26.34 \pm 4.3$ \\
Ca, mg/dL & $186 \pm 0.08$ & $140 \pm 0.05$ & $131 \pm 0.05$ & $121 \pm 0.03$ \\
P, mg/dL & $158 \pm 0.06$ & $128 \pm 0.04$ & $96 \pm 0.04$ & $78 \pm 0.05$ \\
\hline
\end{tabular}

${ }^{1}$ Each day, a.m. and p.m. colostrum samples were composited for analysis $(n=40)$.

${ }^{2}$ Milk storage tank samples $(\mathrm{n}=30)$.

${ }^{3} \mathrm{ND}=$ Not determined.

by each calf were measured at 5 -d intervals throughout the experiment. Polythene sheets were attached around each feeding bucket to account for wastage of calf starter and hays. Calf starter, MGS, KGS, and feed refusals were sampled and analyzed for DM and CP by the methods of AOAC (1990).

Intake of calf starter, MGS, KGS, and DM and CP of solid feed by the calves in STEP and conventional groups were calculated for each of the 3 phases of the experiment: pre-STEP, post-STEP, and postweaning (d 51 to 90). Average weight gain, total DMI (milk solids, starter, and hay), and feed efficiency (feed efficiency = $\mathrm{kg}$ of BW gain/kg of total DMI) were calculated for 4 different periods: pre-STEP, post-STEP, preweaning (d 1 to 50), and postweaning.

Jugular blood samples were collected $30 \mathrm{~min}$ before morning feeding $(0730 \mathrm{~h})$ on d 10, 20, 30, 40, 50, and 60 of the experiment in evacuated tubes $(5 \mathrm{~mL})$ without any anticoagulant. These samples were centrifuged at $1,000 \times g$ for $20 \mathrm{~min}$, and serum was partitioned into aliquots and stored at $-20^{\circ} \mathrm{C}$ until analyzed for glucose, total protein, albumin, BUN, triglycerides, glutamic oxaloacetic transaminase (GOT), glutamic pyruvic transaminase (GPT), lactate dehydrogenase (LDH), and creatinine by serum analyzer (Arco PC; Biotenica Instruments, Rome, Italy).

Fecal scoring for the determination of fecal fluidity, consistency, odor, and days scoured was conducted daily in the morning $(0800 \mathrm{~h})$ using the procedure of Larson et al. (1977). Fecal scoring was as follows: for fecal fluidity, $1=$ normal, $2=$ soft, $3=$ runny, and $4=$ watery; for fecal consistency, $1=$ normal, $2=$ foamy, $3=$ mucousy, $4=$ sticky, and 5 = constipated; for fecal odor, $1=$ normal, 2 = slightly offensive, or $3=$ highly offensive. A scour day was recorded for fecal fluidity $>3$, fecal consistency $>3$, and fecal odor $>2$. When fecal score exceeded 2 (average of fluidity, consistency, and order) or when a calf exhibited other signs of disease (fever or cough), antibiotic (sulfadimethoxine sodium, $55 \mathrm{mg} / \mathrm{kg}$ of BW daily; Green Cross Veterinary Products Co. Ltd., Yongin, South Korea) therapy was initiated. The antibiotic therapy was continued until visual signs of disease disappeared (maximum for $5 \mathrm{~d}$ ). Scours were also treated with electrolyte therapy (Eltradd, $3 \mathrm{~g} / \mathrm{L}$ in drinking water; Byer Animal Health Co., Suwan, South Korea).

\section{Statistical Analysis}

Data on milk intake, feed consumption (starter and hay), and growth performance are expressed as means \pm SEM. Overall differences in feed and nutrient intake were evaluated by means of Wilcoxon's 2-sample test (SAS Institute, 1994) because of the lack of normal distribution of data. Treatment differences of overall growth performance and weekly mean fecal scouring (scouring score $\times$ scouring days) data were evaluated by Student's $t$-test. For time and treatment differences, concentrations of blood metabolites were evaluated using the RANDOM and REPEATED methods of the MIXED procedure of SAS (SAS Institute, 1994). Treatment (i.e., conventional and STEP-milk feeding) and time were used as fixed effects and the individual calves were used as random effects. For analyses of differences in time pattern between groups, the interaction (treatment $\times$ time) was included in the model. Treatment differences at specific time points were localized by Bonferroni's $t$-test $(P<0.05)$.

\section{RESULTS}

Mean daily milk consumption by the calves fed through the STEP procedure was greater $(P<0.05)$ than those fed conventionally during both pre-STEP and post-STEP periods (Figure 1). Calves fed through the STEP procedure consumed 92.3, 19.4, and $62.4 \%$ 


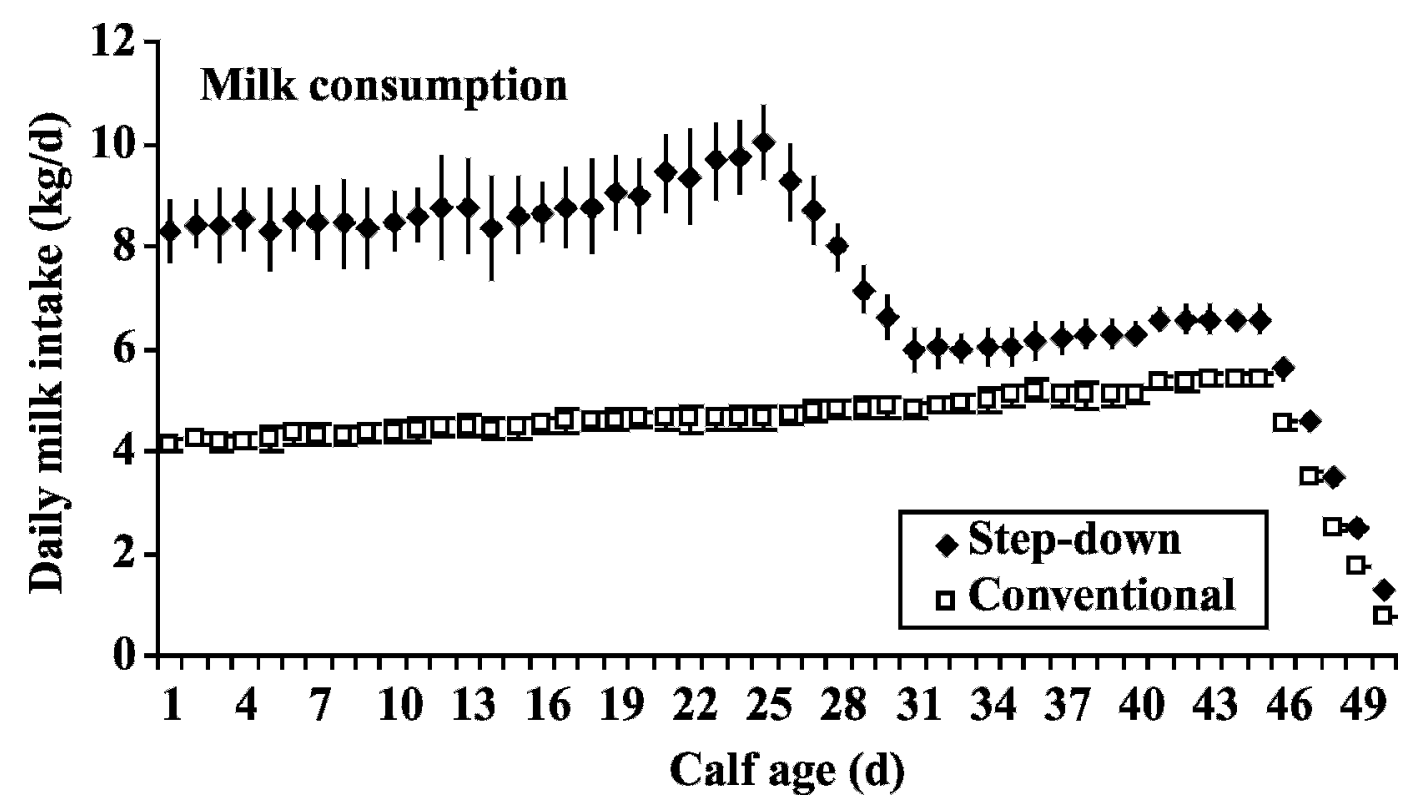

Figure 1. Mean ( \pm SE) daily intake of milk, measured in kilograms. Values are shown separately for Holstein female calves fed milk either conventionally $(\mathrm{n}=20)$ or through step-down (STEP, $\mathrm{n}=20$ ) procedures. In the conventional method, the calves were fed colostrum for $3 \mathrm{~d}$ and then milk at the rate of $10 \%$ of BW until $45 \mathrm{~d}$ of age. In the STEP method, the calves were given colostrum for $3 \mathrm{~d}$ and then milk until $25 \mathrm{~d}$ of age at $20 \%$ of BW, which was gradually reduced (between d 26 and 30) to $10 \%$ of BW for the remaining $15 \mathrm{~d}$ of the weaning period. Calves in both conventional and STEP groups were weaned gradually by diluting milk with water between 46 and $50 \mathrm{~d}$ of age.

more milk than conventionally fed calves during preSTEP, post-STEP, and preweaning periods, respectively (Table 3 ).

Solid feed consumption was increased by the calves fed through conventional and STEP methods with their age; however, a rapid increase in intake of both calf starter and hay was observed after d 30 in calves fed milk through the STEP procedure (Figure 2). Conventionally milk-fed calves showed a steady increase in the consumption of solid feed throughout the preweaning period. The consumption of solid feed by calves in both groups was markedly increased during weaning and within few weeks after weaning.

Consumption of starter and hay were greater $(P<$ $0.05)$ during the pre-STEP period and lesser $(P<0.02)$ during post-STEP and preweaning periods in calves fed milk through conventional method compared with STEP-fed calves (Table 3). During the pre-STEP period, daily consumption of starter, MGS, and KGS was 57.5, 58.6 , and $61.1 \%$ greater, respectively, in calves fed milk conventionally than in those fed by the STEP method (Table 3). However, STEP calves consumed 39.3, 31.9, and $43.9 \%$ more starter, MGS, and KGS daily, respectively, compared with those fed conventionally during the post-STEP period. Respective daily consumption of these feeds was 30.2, 33.6, and 39.0\% greater in STEPfed calves than in those fed conventionally during the postweaning period.
Conventionally fed calves consumed, respectively, 58.7 and $59.4 \%$ more DM and CP than those fed through the STEP method during the pre-STEP period. Daily consumption of DM and CP was, respectively, 38.5 and 40.4\% greater in STEP-fed calves than in those fed conventionally during the post-STEP period. The respective intakes of these nutrients during the overall postweaning period were 31.3 and $36.6 \%$ greater in calves fed using the conventional method when compared with those fed using the STEP method (Table 3).

Mean $( \pm$ SEM) BW of STEP and conventional calves are shown in Figure 3. Average birth weights of the calves in conventional $(44.6 \pm 1.30 \mathrm{~kg})$ and STEP $(44.0$ $\pm 1.41 \mathrm{~kg}$ ) groups were the same. Calves fed milk through the STEP procedure attained 64.24, 79.50, and $111.1 \mathrm{~kg}$ of BW compared with 54.2, 65.0, and 88.20 $\mathrm{kg}$ for conventionally fed calves at d 30 (STEP), 50 (weaning), and 90 (postweaning) of age, respectively (Table 4). Calves fed milk by the STEP procedure gained $110.8,41.3,74.0$, and $36.25 \%$ more BW than those fed conventionally during pre-STEP, post-STEP, preweaning, and postweaning periods, respectively. The STEP calves consumed, respectively, 96.6, 28.4, 53.0, and $25.2 \%$ more total DM than those fed conventionally.

Feed efficiency of Holstein female calves during preSTEP, post-STEP, and preweaning was greater $(P<$ 0.02) with STEP milk feeding compared with the conventional method (Table 4). However, feed efficiency 
Table 3. Average daily milk, starter, klein grass hay, mixed grass hay, and nutrient intakes by Holstein female calves fed milk either through the step-down (STEP; $\mathrm{n}=20$ ) or conventional $(\mathrm{n}=20)$ procedure $^{1}$

\begin{tabular}{llll}
\hline & \multicolumn{2}{c}{ Feeding method } & \\
\cline { 2 - 3 } Trait $^{2}$ & Conventional & STEP & SEM \\
\hline Milk intake, kg & & & \\
Pre-STEP & $4.55^{\mathrm{b}}$ & $8.75^{\mathrm{a}}$ & 0.60 \\
Post-STEP & $4.74^{\mathrm{b}}$ & $5.66^{\mathrm{a}}$ & 0.23 \\
Preweaning & $4.63^{\mathrm{b}}$ & $7.52^{\mathrm{a}}$ & 0.46 \\
Starter intake, kg & & & \\
Pre-STEP & $0.189^{\mathrm{a}}$ & $0.120^{\mathrm{b}}$ & 0.05 \\
Post-STEP & $0.611^{\mathrm{b}}$ & $0.851^{\mathrm{a}}$ & 0.08 \\
Postweaning & $1.92^{\mathrm{b}}$ & $2.50^{\mathrm{a}}$ & 0.12 \\
Klein grass hay, kg & & & \\
Pre-STEP & $0.046^{\mathrm{a}}$ & $0.029^{\mathrm{b}}$ & 0.01 \\
Post-STEP & $0.097^{\mathrm{b}}$ & $0.128^{\mathrm{a}}$ & 0.02 \\
Postweaning & $0.295^{\mathrm{b}}$ & $0.394^{\mathrm{a}}$ & 0.04 \\
Mixed grass hay, kg & & & \\
Pre-STEP & $0.029^{\mathrm{a}}$ & $0.018^{\mathrm{b}}$ & 0.01 \\
Post-STEP & $0.066^{\mathrm{b}}$ & $0.095^{\mathrm{a}}$ & 0.05 \\
Postweaning & $0.241^{\mathrm{b}}$ & $0.335^{\mathrm{a}}$ & 0.05 \\
DM, ${ }^{3}$ kg & & & \\
Pre-STEP & $0.265^{\mathrm{a}}$ & $0.167^{\mathrm{b}}$ & 0.03 \\
Post-STEP & $0.78^{\mathrm{b}}$ & $1.08^{\mathrm{a}}$ & 0.11 \\
Postweaning & $2.46^{\mathrm{b}}$ & $3.23^{\mathrm{a}}$ & 0.1 \\
CP, ${ }^{3}$ kg & & & \\
Pre-STEP & $0.051^{\mathrm{a}}$ & $0.032^{\mathrm{b}}$ & 0.01 \\
Post-STEP & $0.155^{\mathrm{b}}$ & $0.217^{\mathrm{a}}$ & 0.02 \\
Postweaning & $0.410^{\mathrm{b}}$ & $0.561^{\mathrm{a}}$ & 0.02 \\
\hline Po & & & \\
\hline
\end{tabular}

${ }^{\mathrm{a}, \mathrm{b}}$ Within traits, means with different superscript letters are significantly different $(P<0.05)$.

${ }^{1}$ In the conventional method, the calves were fed colostrum for 3 $\mathrm{d}$ and then milk at $10 \%$ of BW until $45 \mathrm{~d}$ of age. In the STEP method, the calves were given colostrum for $3 \mathrm{~d}$ and then milk until $25 \mathrm{~d}$ of age at $20 \%$ of BW, which was gradually reduced (between d 26 and 30 ) to $10 \%$ of BW for the remaining $15 \mathrm{~d}$ of weaning period. Calves in both the conventional and STEP groups were weaned gradually by diluting milk with water between 46 and $50 \mathrm{~d}$ of age.

${ }^{2}$ Periods: Pre-STEP $=$ from 1 to $30 \mathrm{~d}$ of age; post-STEP $=$ from 31 to $50 \mathrm{~d}$ of age; preweaning = from 1 to $50 \mathrm{~d}$ of age; and postweaning = from 51 to $90 \mathrm{~d}$ of age.

${ }^{3}$ Average nutrient intake of starter and hay (klein grass and mixed grass).

of STEP calves after weaning was numerically higher compared with conventional calves.

Blood glucose concentration was initially increased $(P<0.02)$ up to $\mathrm{d} 30$ of age and thereafter decreased $(P<0.02)$ in the calves (Table 5). However, reduction in blood glucose was more pronounced after d 30 in calves fed milk by the STEP procedure compared with those fed conventionally. Blood glucose concentration was lesser $(P<0.03)$ in calves fed milk by the STEP procedure than in those fed conventionally at $d 40,50$, and 60 of age. Treatment $\times$ time interaction for blood glucose concentration at d 60 was significant $(P<0.02)$. Blood total protein and albumin concentrations were increased $(P<0.03$ and $P<0.02$, respectively) with age of calves; however, no effect of treatment was found. The BUN was increased $(P<0.02)$ with age of calves; however, its concentration was greater $(P<0.02)$ in calves fed milk by the STEP-procedure than in those fed conventionally at d 50 and 60 of age. Blood triglycerides were affected $(P<0.04)$ by the calf age, and the concentration was greater $(P<0.02)$ at $\mathrm{d} 10,20$, and 30 in calves fed by the STEP procedure than in those fed conventionally. Treatment $\times$ time interaction for blood triglycerides concentration in calves during $60 \mathrm{~d}$ was significant $(P<0.03)$. Blood GOT, GPT, and LDH concentrations were increased $(P<0.05)$ with increasing age of the calves, but no effect of treatment was found. Blood creatinine contents were decreased $(P<0.02)$ in calves with age; however, the amount of milk fed did not influence blood creatinine concentration.

Occurrence of diarrhea was higher $(P<0.05)$ in calves fed milk through the conventional system than in those fed by the STEP procedure during wk 3 and 4 of age. During earlier and later periods, however, the incidence of diarrhea was low and not different between treatments (Figure 4). No other sign of disease was noticed in calves fed milk either by the STEP or conventional method.

\section{DISCUSSION}

Calves safely consumed greater amounts of milk without any noticeable increase in diarrhea when fed by the STEP procedure compared with the conventional system. Similar results were documented previously by Hammell et al. (1988), Appleby et al. (2001), and Jasper and Weary (2002) by feeding ad libitum amounts of milk to dairy calves. Greater daily milk consumption in ad libitum milk-fed calves can increase their digestive capacity (de Passillé et al. 1992) and thus probably enable them to handle a large quantity of milk. Presence of several growth factors, hormones, or both in colostrum and milk could enhance the growth and maturation of the gastrointestinal tract of calves (Blum and Baumrucker, 2002). High incidence of diarrhea is usually related to sanitary, management, and housing conditions of the calves rather than their daily amounts of milk intake (Hammon et al., 2002). Calves can consume and digest greater amounts of milk than typically given under a conventional feeding system, particularly when provided in small and frequent meals that are similar to those observed under natural conditions (Albright and Arave, 1997). Significantly greater milk consumption by the STEP calves compared with those fed conventionally during the post-STEP period (milk feeding at $10 \%$ of $\mathrm{BW}$ ) was the function of higher BW, which they attained earlier during the pre-STEP period because of greater milk consumption.

Increased milk consumption during the pre-STEP period probably depressed the intake of both starter and 

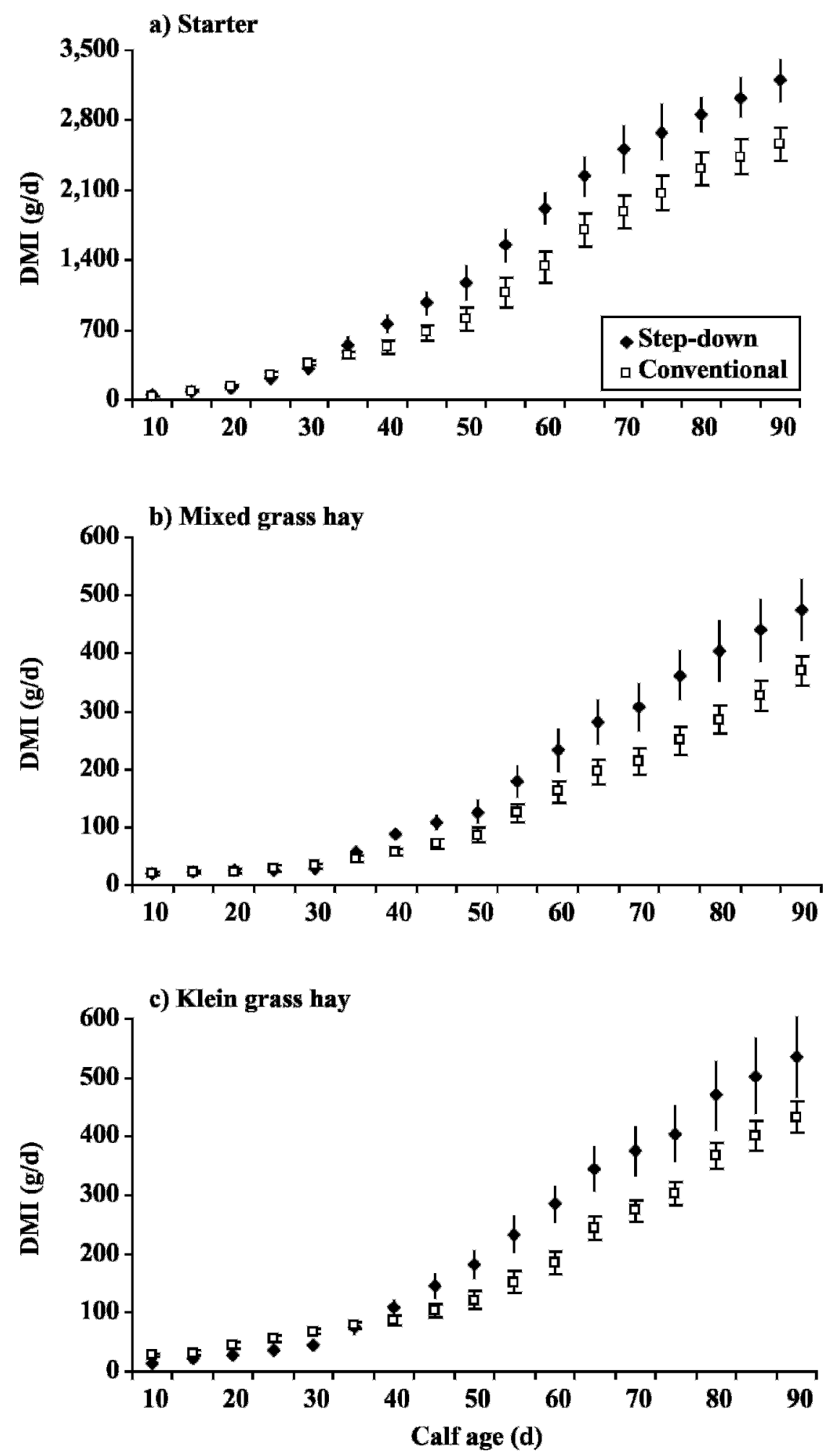

Figure 2. Mean ( \pm SE) DMI of (a) starter, (b) mixed grass hay, and (c) klein grass hay. Values are shown separately for Holstein female calves fed milk either conventionally $(n=20)$ or through step-down (STEP; $n=20)$ procedures. In the conventional method, the calves were fed colostrum for $3 \mathrm{~d}$ and then milk at the rate of $10 \%$ of BW until $45 \mathrm{~d}$ of age. In the STEP method, the calves were given colostrum for $3 \mathrm{~d}$ and then milk until $25 \mathrm{~d}$ of age at $20 \%$ of BW, which was gradually reduced (between d 26 and 30) to 10\% of BW for the remaining 15 $\mathrm{d}$ of the weaning period. Calves in both the conventional and STEP groups were weaned gradually by diluting milk with water between 46 and $50 \mathrm{~d}$ of age. 


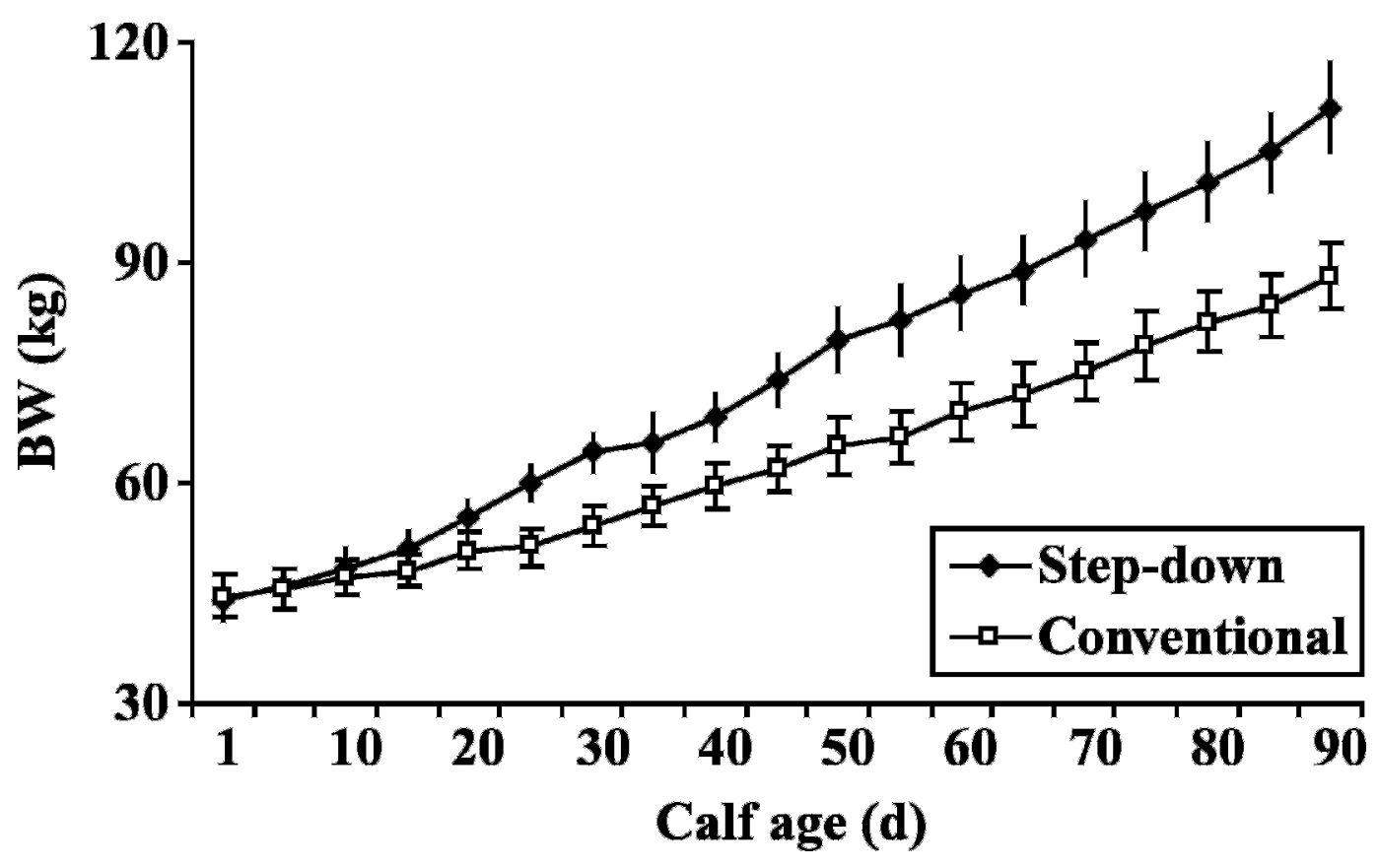

Figure 3. Mean $( \pm \mathrm{SE}) \mathrm{BW}$ of Holstein female calves. Values are shown separately for Holstein female calves fed milk either conventionally $(\mathrm{n}=20)$ or through step-down (STEP; $\mathrm{n}=20$ ) procedures. In the conventional method, the calves were fed colostrum for $3 \mathrm{~d}$ and then milk at the rate of $10 \%$ of BW until $45 \mathrm{~d}$ of age. In the STEP method, the calves were given colostrum for $3 \mathrm{~d}$ and then milk until $25 \mathrm{~d}$ of age at $20 \%$ of BW, which was gradually reduced (between d 26 and 30) to $10 \%$ of BW for the remaining $15 \mathrm{~d}$ of the weaning period. Calves in both the conventional and STEP groups were weaned gradually by diluting milk with water between 46 and $50 \mathrm{~d}$ of age.

hay by the calves fed milk through the STEP procedure. Previously, other researchers (Appleby et al., 2001; Hammon et al., 2002; Jasper and Weary, 2002) reported a depression in solid feed consumption when they fed higher amounts of milk to dairy calves. In the present study, the amount of milk fed ( $20 \%$ of BW) to the dairy calves through the STEP procedure during the preSTEP period was almost comparable to the amount of milk that calves drank when offered ad libitum through an automated system (Hammon et al., 2002) or using artificial teats (Appleby et al., 2001). Thickett et al. (1983) also reported a depression in starter and hay intake with ad libitum milk consumption in calves. When calves are offered milk ad libitum, they habitually eat less dry feed (Fiems et al., 1982; Bøe and Havrevoll, 1993). Furthermore, the continuous gut filling (curd formation) because of higher milk consumption may have prevented the STEP-fed calves from eating more solid feed during the pre-STEP period.

An increase in solid feed intake during the post-STEP period by the calves fed through the STEP procedure may be attributed to the reduced milk supply and associated decrease in nutrient availability. The reduction in milk availability to the STEP calves during the postSTEP period possibly triggered the hyperphagic response (not estimated in this study), which would result in increased solid feed intake that likely compensated for reduced nutrient availability. It may be that the greater BW and increased digestive tract capacity (Bøe and Havrevoll, 1993), resulting from the increased milk intake of STEP calves during the pre-STEP phase, resulted in a greater demand for nutrients and an increased consumption of solid feed during the post-STEP phase. Church et al. (1980) also reported that calves fed low levels of milk consumed more forage to compensate for the lower nutrient supply from milk consumption. Similarly, Abdelsamei et al. (2005) indicated that a decrease in milk replacer consumption linearly increased the intake of hay by Holstein calves. Consumption of more solid feed before weaning by STEP calves probably resulted in the start of some ruminal activity (fermentation) earlier than in those fed conventionally (Abdelsamei et al., 2005). The earlier initiation of solid feed consumption and possible related ruminal activity in STEP calves can mitigate the negative effects of ad libitum milk intake on preweaning and postweaning feed intake, growth, and performance of dairy calves noticed earlier in many studies (Bøe and Havrevoll, 1993; Baldwin et al., 2004; Jensen, 2004). The increased feed intake observed in STEP-fed calves during the postweaning period may be due to the increase in solid feed consumption observed during the preweaning period, which resulted in a greater BW and improved rumen function (Baldwin et al., 2004). 
Table 4. Body weight, BW gain, DMI, and feed efficiency in Holstein female calves on step-down (STEP; $\mathrm{n}=20)$ or conventional $(\mathrm{n}=20)$ milk feeding ${ }^{1}$

\begin{tabular}{lccc}
\hline & \multicolumn{2}{c}{ Feeding method } & \\
\cline { 2 - 3 } Trait $^{2}$ & Conventional & STEP & SE \\
\hline BW, kg & & & \\
at birth & 44.6 & 44.0 & 1.1 \\
at STEP (d 30) & $54.2^{\mathrm{b}}$ & $64.2^{\mathrm{a}}$ & 3.2 \\
at weaning (d 50) & $65.0^{\mathrm{b}}$ & $79.5^{\mathrm{a}}$ & 3.8 \\
at 90 d & $88.2^{\mathrm{b}}$ & $111.1^{\mathrm{a}}$ & 5.7 \\
BW gain, kg & & & \\
Pre-STEP & $9.6^{\mathrm{b}}$ & $20.2^{\mathrm{a}}$ & 1.2 \\
Post-STEP & $10.8^{\mathrm{b}}$ & $15.3^{\mathrm{a}}$ & 1.9 \\
Preweaning & $20.4^{\mathrm{b}}$ & $35.5^{\mathrm{a}}$ & 2.2 \\
Postweaning & $23.2^{\mathrm{b}}$ & $31.6^{\mathrm{a}}$ & 3.4 \\
Total DMI, ${ }^{3} \mathrm{~kg}$ & & & \\
Pre-STEP & $22.6^{\mathrm{b}}$ & $40.8^{\mathrm{a}}$ & 3.5 \\
Post-STEP & $28.8^{\mathrm{b}}$ & $36.4^{\mathrm{a}}$ & 3.2 \\
Preweaning & $51.4^{\mathrm{b}}$ & $77.2^{\mathrm{a}}$ & 3.4 \\
Postweaning & $98.1^{\mathrm{b}}$ & $122.9^{\mathrm{a}}$ & 4.9 \\
Feed efficiency & & & \\
Pre-STEP & $0.42^{\mathrm{b}}$ & $0.50^{\mathrm{a}}$ & 0.01 \\
Post-STEP & $0.38^{\mathrm{b}}$ & $0.42^{\mathrm{a}}$ & 0.01 \\
Preweaning & $0.40^{\mathrm{b}}$ & $0.46^{\mathrm{a}}$ & 0.01 \\
Postweaning & $0.2^{2}$ & 0.26 & 0.02 \\
\hline
\end{tabular}

a,b Within traits, means with different superscript letters are significantly different $(P<0.05)$.

${ }^{1}$ In the conventional method, the calves were fed colostrum for 3 $\mathrm{d}$ and then milk at the rate of $10 \%$ of BW until $45 \mathrm{~d}$ of age. In the STEP method, the calves were given colostrum for $3 \mathrm{~d}$ and then milk until $25 \mathrm{~d}$ of age at $20 \%$ of BW, which was gradually reduced (between 26 and $30 \mathrm{~d}$ of age) to $10 \%$ of BW for the remaining $15 \mathrm{~d}$ of weaning period. Calves in both the conventional and STEP groups were weaned gradually by diluting milk with water between 46 and $50 \mathrm{~d}$ of age.

${ }^{2}$ Periods: Pre-STEP $=$ from 1 to $30 \mathrm{~d}$ of age; post-STEP = from 31 to $50 \mathrm{~d}$ of age; preweaning $=$ from 1 to $50 \mathrm{~d}$ of age; and postweaning $=$ from 51 to $90 \mathrm{~d}$ of age.

${ }^{3} \mathrm{DMI}$ includes milk, starter, and hay.

${ }^{4}$ Feed efficiency $=\mathrm{kg}$ of $\mathrm{BW}$ gain $/ \mathrm{kg}$ of DMI.

Although the vocalizations were not quantified in the current study, farm staff did notice loud and deep calls in conventional calves during $2 \mathrm{~h}$ before morning and evening milk feeding throughout the preweaning period. However, such calls in STEP calves only occurred during $\mathrm{d} 29$ to 33 , probably in response to the reduced milk supply. At weaning, loud calls were observed in both STEP-fed (d 49 to 53) and conventional milk-fed calves (d 48 to 55). Watts and Stookey (2000) reported that vocalization might be viewed as a subjective commentary by an individual on its own internal state. The vocal behavior of cattle is potentially a useful indicator of their physiological and psychological functioning. In the present study, loud and deep calls of calves fed conventionally during the entire preweaning period may have indicated a condition of physiological distress, probably because of low milk and nutrient availability.

Decreases in blood glucose levels were observed in calves fed both feeding regimens as they grew older.
This change has been attributed to the physiological shift in the primary energy source from glucose to VFA when the rumen in young calves becomes functional (Hammon et al., 2002). In neonatal calves, due to the reflexive closure of the reticular groove and the lack of short-chain fatty acids in the ruminal lumen, the primary source of energetic substrate is glucose derived from intestinal absorption. With the initiation of solid feed consumption, ruminal fermentation proceeds and VFA starts replacing glucose as the energy source (Baldwin et al., 2004). Noticeably lesser blood glucose concentration in STEP-fed calves than in those fed conventionally at weaning and postweaning may be ascribed to more solid feed consumption, likely better ruminal activity and fermentation (Gálfi et al., 1991), and thus possibly more reliance on end products to derive energy needs (Hammon et al., 2002; Baldwin et al., 2004).

Higher blood total protein, albumin, and BUN concentrations in older calves were probably the function of more DM and CP consumption. Higher BUN at $d$ 50 (weaning) and 60 in calves fed through the STEP procedure compared with those fed conventionally may be due to the higher rates of protein degradation or AA deamination because of higher protein intake and probably a better functional rumen (Hadorn et al., 1997). Higher concentration of BUN is also an index of the renal dysfunction; however, the creatinine concentration in the calves fed through both methods was in the safe range (Hadorn et al., 1997; Hammon et al., 2002), reduced as calves grew older, and did not differ between treatments. Higher concentrations of GOT, GPT, and LDH in calves are usually related to the anomalies of liver metabolism and diarrhea. In the present study the concentration of these enzymes were within the normal and safe range as previously described by Rauprich et al. (2000). Lactate in the peripheral circulation can originate from ruminal fermentation, propionate metabolism in the ruminal wall, and endogenous production from glycolysis. Stevens and Stettler (1966) reported that a reduced capacity for glycolysis in both liver and muscle of calves was associated with a functional rumen. Higher blood triglycerides in STEP-fed calves compared with those fed conventionally during post-STEP may be attributed to the higher fat absorption because of more milk consumption (Hadorn et al., 1997).

Higher BW of STEP calves compared with those fed conventionally during the pre-STEP period was probably the function of more nutrients available from considerably greater milk consumption. Previously, Jasper and Weary (2002) fed milk ad libitum to dairy calves for the first $4 \mathrm{wk}$ and reported that calves fed ad libitum drank $89 \%$ more milk and gained $63 \%$ more BW at weaning than those fed conventionally. Significantly 
Table 5. Blood serum concentrations of metabolites in Holstein female calves fed milk either by conventional or step-down procedures ${ }^{1}$

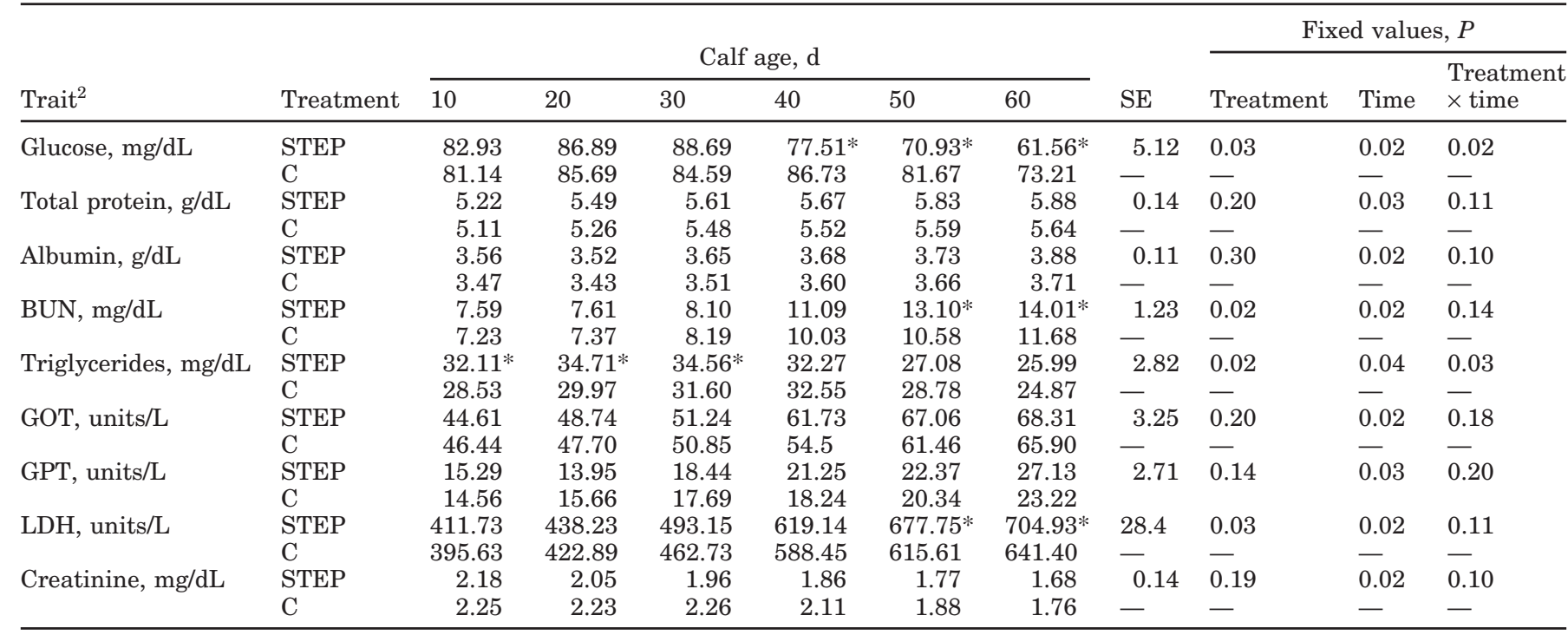

${ }^{1}$ In the conventional method, the calves were fed colostrum for $3 \mathrm{~d}$ and then milk at the rate of $10 \%$ of BW until $45 \mathrm{~d}$ of age. In the STEP method, the calves were given colostrum for $3 \mathrm{~d}$ and then milk until $25 \mathrm{~d}$ of age at $20 \%$ of BW, which was gradually reduced (between d 26 and 30) to $10 \%$ of BW for the remaining $15 \mathrm{~d}$ of weaning period. Calves in both the conventional and STEP groups were weaned gradually by diluting milk with water between $\mathrm{d} 46$ and 50 of age.

${ }^{2} \mathrm{GOT}=$ Glutamic oxaloacetic transaminase; GPT = glutamic pyruvic transaminase; LDH = lactate dehydrogenase.

*Means are different between treatments $(P<0.05)$.

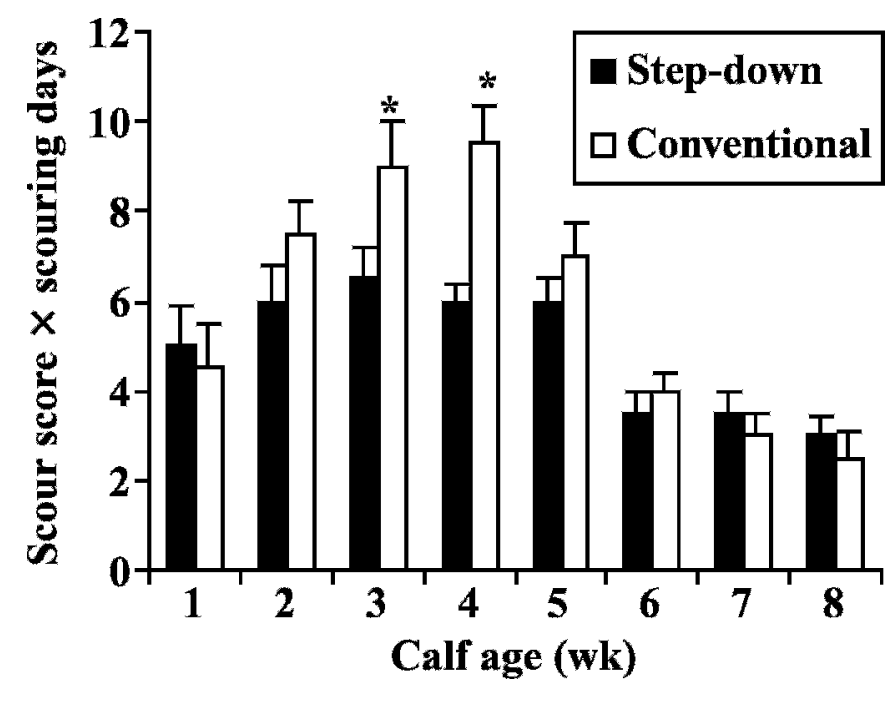

Figure 4. Mean ( \pm SE) weekly fecal scores of Holstein female calves fed milk either through conventional $(\mathrm{n}=20)$ or step-down (STEP; $\mathrm{n}=20$ ) procedures. In the conventional method, the calves were fed colostrum for $3 \mathrm{~d}$ and then milk at the rate of $10 \%$ of BW until $45 \mathrm{~d}$ of age. In the STEP method, the calves were given colostrum for $3 \mathrm{~d}$ and then milk until $25 \mathrm{~d}$ of age at $20 \%$ of BW, which was gradually reduced (between d 26 and 30 ) to $10 \%$ of BW for the remaining $15 \mathrm{~d}$ of the weaning period. Calves in both conventional and STEP groups were weaned gradually by diluting milk with water between 46 and $50 \mathrm{~d}$ of age. *Difference between treatments was significant $(P<0.05)$. greater BW gain during the post-STEP period in calves fed milk through the STEP method may be ascribed to more consumption of starter and hays. The quantity of milk consumed by STEP calves during the post-STEP period was also higher than those fed conventionally. Greater BW gain in STEP calves compared with those fed conventionally during the preweaning period may be ascribed to higher consumption of both solid and liquid feed. This early growth advantage is of immense importance for female dairy calves, which could lower the age at first calving (Jasper and Weary, 2002) without posing negative effects on their mammary system development (Sjersen et al., 2000). Furthermore, because of greater DMI from both milk and solid feed, the feed efficiency was better in STEP calves than in those fed conventionally.

\section{CONCLUSIONS}

The calves on step-down milk feeding consumed more solid feed and gained greater BW compared with those fed milk conventionally. Provision of milk to calves using the step-down method could prevent the problems of depressed solid feed consumption associated with ad libitum milk intake and of poor weight gain with the conventional method. However, further research is warranted to elicit the endocrinological and gut development response of Holstein calves fed through the stepdown milk feeding system. 


\section{ACKNOWLEDGMENTS}

This study was conducted as a part of the postdoctoral research project funded by the National Livestock Research Institute, Rural Development Administration, South Korea. The authors are thankful to Yun-Tai Kim and Jay-Sik Lee for their assistance in feed analysis.

\section{REFERENCES}

Abdelsamei, A. H., D. G. Fox, L. O. Tedeschi, M. L. Thonney, D. J. Ketchen, and J. R. Stouffer. 2005. The effect of milk intake on forage intake and growth of nursing calves. J. Anim. Sci. 83:940-947.

Anderson, M. J., M. Khoyloo, and J. L. Walters. 1982. Effect of feeding whole cottonseed on intake, body weight and reticulo-rumen development of young Holstein calves. J. Dairy Sci. 65:764-772.

Albright, L. L., and C. W. Arave. 1997. The Behaviour of Cattle. CAB International, Wallingford, UK.

AOAC. 1990. Official Methods of Analysis. 15th ed. Association of Official Analytical Chemists, Arlington, VA.

Appleby, M. C., D. M. Weary, and B. Chua. 2001. Performance and feeding behavior of calves on ad libitum milk from artificial teats. Appl. Anim. Behav. Sci. 74:191-201.

Baldwin, R. L., VI, K. R. McLeod, J. L. Klotz, and R. N. Heitmann. 2004. Rumen development, intestinal growth and hepatic metabolism in the pre- and post-weaning ruminant. J. Dairy Sci. 87(E Suppl.):E55-E65.

Bar-Peled, U., B. Robinzon, E. Maltz, H. Tagari, Y. Folman, I. Bruckental, H. Voet, H. Gacitua, and A. R. Lehrer. 1997. Increased weight gain and effects on production parameters of Holstein heifer calves that were allowed to suckle from birth to six weeks of age. J. Dairy Sci. 80:2523-2528.

Blum, J. W., and C. R. Baumrucker. 2002. Colostral and milk insulinlike growth factors and related substances: Mammary gland and neonatal (intestinal and systemic) targets. Domest. Anim. Endocrinol. 23:101-110.

Bøe, K., and Ø. Havrevoll. 1993. Cold housing and computer-controlled milk feeding for dairy calves: Behavior and performance. Anim. Prod. 57:183-191.

Chua, B., E. Coenen, J. van Delen, and D. M. Weary. 2002. Effects of pair versus individual housing on the behavior and performance of dairy calves. J. Dairy Sci. 85:360-364.

Church, D. C., D. L. Gorrill, and R. G. Warner. 1980. Feeding and nutrition of young calves. Pages 164-183 in Digestive Physiology and Nutrition of Ruminants. D. C. Church, ed. O\&B Books, Corvallis, OR.

de Passillé, A. M. B., J. H. M. Metz, and P. R. Wiepkema. 1992. Does drinking milk stimulate sucking in young calves? Appl. Anim. Behav. Sci. 34:23-36.

Egli, C. P., and J. W. Blum. 1998. Clinical, haematological, metabolic and endocrine traits during the first three months of life of suckling Simmentaler calves held in a cow-calf operation. Zentralbl. Veterinaermed. Reihe A 45:99-118.

Fiems, L. O., Ch. V. Boucqué, B. G. Cottyn, and F. X. Buysse. 1982. Effect of feeding techniques and age at weaning on the performances of bucket-fed and suckling reared calves. Pages 149-167 in Welfare and Husbandry of Calves, Current Topics in Veteri- nary Medicine and Animal Science. Vol. 19. J. P. Signoret, ed. Springer, Berlin, Germany.

Flower, F., and D. M. Weary. 2001. Effects of early separation on the dairy cow and calf: 2 . Separation at 1 day and 2 weeks after birth. Appl. Anim. Behav. Sci. 70:275-284.

Gálfi, P., S. Neogrády, and T. Sakata. 1991. Effects of volatile fatty acids on the epithelial cell proliferation of the digestive tract and its hormonal mediation. Pages 49-59 in Physiological Aspects of Digestion and Metabolism in Ruminants: Proceedings of the Seventh International Symposium on Ruminant Physiology. T. Tsuda, Y. Sasaki, and R. Kawashima, ed. Academic Press, Inc., San Diego, CA.

Hadorn, U., H. Hammon, R. M. Bruckmaier, and J. W. Blum. 1997. Delaying colostrum intake by one day has important effects on metabolic traits and on gastrointestinal and metabolic hormones in neonatal calves. J. Nutr. 127:2011-2023.

Hammell, K. L., J. H. M. Metz, and P. Mekking. 1988. Sucking behaviour of dairy calves fed milk ad libitum by bucket or teat. Appl. Anim. Behav. Sci. 20:275-285.

Hammon, H. M., G. Schiessler, A. Nussbaum, and J. W. Blum. 2002. Feed intake patterns, growth performance, and metabolic and endocrine traits in calves fed unlimited amounts of colostrum and milk by automate, starting in the neonatal period. J. Dairy Sci. 85:3352-3362.

Huber, J. T., A. G. Silva, O. F. Campos, and C. M. Mathieu. 1984. Influence of different amounts of milk on performance, health, and absorption capability of baby calves. J. Dairy Sci. 67:2964-2969.

Jasper, J., and D. M. Weary. 2002. Effects of ad libitum milk intake on dairy calves. J. Dairy Sci. 85:3054-3058.

Jensen, M. B. 2004. Computer-controlled milk feeding of dairy calves: The effects of number of calves per feeder and number of milk portions on use of feeder and social behavior. J. Dairy Sci. 87:3428-3438

Larson, L. L., F. G. Owen, J. L. Albright, R. D. Appleman, R. C. Lamb, and L. D. Muller. 1977. Guidelines toward more uniformity in measuring and reporting calf experimental data. J. Dairy Sci. 60:989-991.

National Research Council. 2001. Nutrient Requirements of Dairy Cattle. 7th rev. ed. Natl. Acad. Sci., Washington, DC.

Pollack, J. M., T. G. Rowan, J. B. Dixon, S. D. Carter, D. Spiller, and H. Warenius. 1993. Alteration of cellular immune responses by nutrition and weaning in calves. Res. Vet. Sci. 55:298-306.

Rauprich, A. B. E., H. M. Hammon, and J. W. Blum. 2000. Influence of feeding different amounts of first colostrum on metabolic, endocrine, and health status, and growth performance in neonatal calves. J. Anim. Sci. 78:896-908

SAS Institute. 1994. SAS User's Guide. Statistics. Version $6.11 \mathrm{ed}$. SAS Institute, Inc., Cary, NC.

Sjersen, K., S. Purup, M. Vestergaard, and J. Foldager. 2000. High body weight gain and reduced bovine mammary growth: Physiological basis and implications for milk yield. Domest. Anim. Endocrinol. 19:93-104.

Stevens, C. E., and B. K. Stettler. 1966. Factors affecting the transport of volatile fatty acids across rumen epithelium. Am. J. Physiol. 210:365-372.

Thickett, W. S., N. H. Cuthbert, T. D. A. Brigstocke, M. A. Lindeman, and P. N. Wilson. 1983. A note on the performance and management of calves reared on cold acidified milk replacer ad libitum. Anim. Prod. 36:147-150.

Watts, J. M., and J. M. Stookey. 2000. Vocal behaviour in cattle: The animal's commentary on its biological processes and welfare. Appl. Anim. Behav. Sci. 67:15-33. 